\title{
"Is enlightenment just a European idea?" An interview with Daya Thussu
}

\author{
Sašo Slaček Brlek*; Jernej Amon Prodnik*; Daya K. Thussu*". \\ * Social Communication Research Centre, Faculty of Social Sciences, University of \\ Ljubljana, Slovenia, saso.brlek-slacek@fdv.uni-lj.si, jernej.amon-prodnik@fdv.uni-lj.si \\ ** University of Westminster, United Kingdom.
}

\begin{abstract}
Interview with Daya Kishan Thussu, Professor of International Communication at the University of Westminster. We discuss his journalistic experience at the Press Trust of India and Gemini News Service, the New World Information and Communication Order and the MacBride report, the rise of BRICS and changes in the sphere of international communications in recent decades, the significance of critical scholarship and the need to internationalize media and communication studies.
\end{abstract}

Keywords: International communication, New World Information and Communication Order, UNESCO, MacBride report, BRICS, China, India.

Daya Kishan Thussu is Professor of International Communication at the University of Westminster in London and the founder and Co-Director of the India Media Centre and research advisor to the China Media Centre. His scholarly interest in issues of international communication is combined with rich practical experience at the Press Trust of India, where he worked in the turbulent years and as Associate Editor in Gemini News Service, an alternative news agency with a strong third-world focus from 1991 to 1995.

He has been teaching, researching and writing about international aspects of media and communication for nearly three decades. His book International Communication - Continuity and Change has established itself as a key text in this area, having been adopted by universities around the world and translated into Mandarin and Korean. His books include: Communicating India's Soft Power: Buddha to Bollywood; Mapping BRICS Media (co-edited with Kaarle Nordenstreng); Media and Terrorism: Global Perspectives (co-edited with Des Freedman); Internationalizing Media Studies; News as Entertainment: The Rise of Global Infotainment; Media on the Move: Global Flow and Contra-Flow; International Communication - Continuity and Change; and Electronic Empires - Global Media and Local Resistance.

$\mathrm{He}$ is also the founder and Managing Editor of the journal Global Media and Communication and Editor-in-Chief of the journal Global Media and China, published in collaboration with Communication University of China. He is series editor for two book series for Routledge: Internationalizing Media Studies and Advances in Internationalizing Media Studies. In 2014, he was honoured with a 'Distinguished Scholar Award' by the International Studies Association.

We spoke at the Faculty of Social Sciences, University of Ljubljana, where Professor Thussu was giving a series of lectures on international communication in May 2016. 


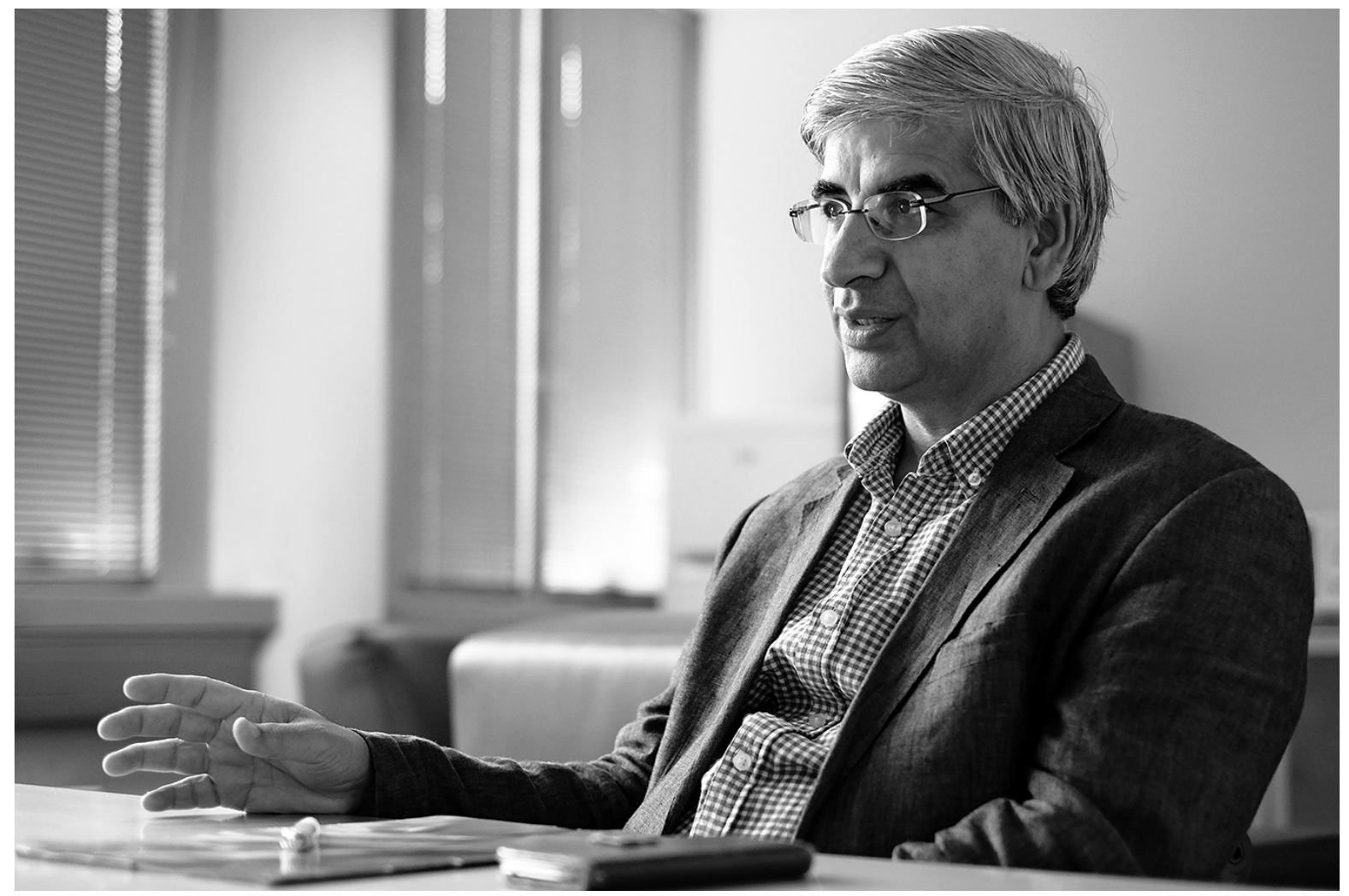

(Photo: Jernej Amon Prodnik)

Sašo: How did you get involved or interested in questions of international communication?

Daya: I'm actually a bit of an oddity in this field because I have a PhD in international relations and I'm one of the very few people, at least in the UK, who is teaching communications with a background in history, politics and international relations.

My academic background was in international relations which helped me to think about international communication as part of international relations. But in my previous life I have also had experience working as a journalist. In India I worked for the Press Trust of India [PTI], which is the largest news agency in India. In fact, when I was there in the 1980s it was the biggest news organisation in the country. I then worked in a very small organisation in London, in a team of only 4 people. It was an alternative news agency called Gemini News Service, which is now defunct, with a Third World-oriented editorial agenda. It covered regions of the world which are normally not in the mainstream media.

That was also a very important learning curve having actually worked in a very busy newsroom in Delhi and working on international news. Because of my academic background, I was interested in the international desk rather than domestic reporting and then working in a very small organisation in London, again with a clearly international focus. I was Associate Editor of Gemini News Service for 4 years, which meant I did most of the work. Gemini was a tiny organisation, you had to do absolutely everything: research, administration, writing, editing, etc.

That combination I think helped me a great deal in my academic career, in the sense that I had the understanding of how the news system works in a national context but also in a transnational context, in a mainstream context, as well as in an alternative environment. 
I moved full time into academia in 1995 and since then my work has been largely about international communication. In fact, I was the second professor of international communication in the UK. The first one was late Phillip Taylor who was a historian by training at the University of Leeds. He was the first chair of International Communication. I got the second professorship in International Communication at the University of Westminster in 2004.

Of course my background was slightly different from Phillip's, he was really a historian. I studied history at University, I also have a Masters in history and a Masters in politics. But my PhD was in International Relations which really helped me in terms of thinking about international media from an international politics perspective and that's what l've been doing since.

Sašo: At what time were you at the Press Trust of India?

Daya: It was from 1983 to 1988. I was there for 5 years, while I was also working for my PhD in Jawaharlal Nehru University in Delhi, which is one of the top universities in India, known for its critical research tradition, especially in social sciences. I was very fortunate that I could combine the two. I had a fantastic supervisor, he said 'fine, you can do this', because my job was such that I could actually work night shifts. It was a desk job and that worked brilliantly for me. I could do my research in the day time and at night I would do news rooms. It was like going to the library and reading lots of newspapers. I loved reading newspapers anyway, but reading them from all over the world - in the pre-Internet age - was doubly rewarding. At PTI, I was working on for what was then the non-aligned news agencies pool [NANAP] and PTI was one of the key news agencies along with Tanjug in that pool. We had a dedicated desk and out of my curiosity and interest in international relations I used to work on it. Most of my colleagues found such work rather boring but I was very interested in terms of how news flows south-south. So again: it was a fantastic experience. I was there for 5 years.

And I was associated with Gemini for 4 years which helped me a great deal in my academic career.

Sašo: And those were very turbulent years. In 1984 came the backlash from the United States and United Kingdom against UNESCO. How did you feel that in your work? Or did you feel it?

Daya: Well actually I came to the UK on a Commonwealth Scholarship as a post-doc in 1988 and I was at the Open University in the UK where I met Oliver Boyd-Barrett who had done very good work on news agencies, pioneering study, and he was involved in a UNESCO project on news exchange mechanisms, which was part the IPDC [International Programme for the Development of Communication] programme. So he found this Indian guy who had news agency experience and who he was interested in working with, as was I. I was very involved in this whole debate because we wrote a report for UNESCO and it was published as a book in 1992. It is called Contra-flow in Global News, published in collaboration with UNESCO. In that book, we addressed some of these issues about global news flow and US domination and what it meant for UNESCO and generally for the NWICO [New World Information and Communication Order] debate. But I was involved in it even before I came to the UK. In India, it was a big debate. In fact, India was one of the key exponents of NWICO which was again interesting because when this debate was at its height in the 1970s, 
Indira Gandhi was the prime minister of India and she had imposed a state of emergency which involved muzzling the press. Thankfully, it was only for two years: 1975 to 1977. During this period, she was going around the world and telling Western media that you guys distort reality, you do this, you do that ... but at home she had journalists arrested and newspapers were shut. It has never happened in India since or before that. It was only those two years. The newspaper, Indian Express, was actually shut down. The authorities just cut of its electricity supplies because it was considered as anti-government.

The new world information and communication order debate was big in India and I had a clear understanding of what the issues were when I came to London. The debates were quite dominant in Indian discourses: intellectual discourse, policy discourse, even in media. In the West, it was a marginal debate, it was a debate in academia. It was not really a big thing.

The UNESCO experience and the US position was not surprising. You know we forget it now but if we go back to the time when these debates were taking place, we were still in the Cold War period. It was a debate about information imperialism that the Russians were very keen to exploit. Russia was using it to score points against the US. And there was this idea of Third-Worldism, Non-Alignment was a big thing in those years.

I had deep intellectual interest in it and therefore I was monitoring it extremely carefully. Then I got an opportunity to work on a project where we had to explore the alternatives, how effective are they etc. And the book came out in 1992 about these news exchange mechanisms. You don't have to depend on Reuters or AP, you can have news-exchange among developing countries. But then the problem was both of quality of journalism in most developing countries as well as the partisan nature of foreign reporting. This was the time of the Iran-Iraq war - the first gulf war - often the narrative in Western media suggests that the gulf war took place in 1991. In fact, there was a 10-year war between Iran and Iraq which claimed one million lives and when I was working at PTI and on the non-aligned agencies pool it was fascinating to see what the Iraqi news agency was saying about the conflict and what Iran's media was saying. They were dramatically opposed, you couldn't use either. I ended up using Tanjug or Reuters etc.

I had seen first-hand what the problem was. When the Americans were saying 'this is all state propaganda and we can't take it seriously' they had a point. How could you trust what the mullahs were saying in Iran? That was just after the revolution in 1979 , while Iraq was led by a dictatorship. And that wasn't an unusual case as much of the so called Third World media were entirely controlled by the state. The media market was too small - so the government held the sway. And the state in many cases was a family. It didn't matter if it was a Marxist or an American clone, they were not representative governments. India was an oddity in that respect because India had a well-established democracy, very sophisticated press, civil society was highly developed and debates were pretty advanced and comprehensive.

We were witnessing a kind of political football between big powers. The unfortunate thing was that they threw the baby out with the bathwater in the sense that the fundamental issues raised in that debate about inequality, about imbalance, about distortions, about representation, were forgotten. They are as valid today as in the 1970s. But the debate was just framed very narrowly about news and news agencies and this whole idea of inequality and imbalance has just gone out of the window. It's unfortunate because NWICO was the first serious multilateral attempt to address these issues at an international level. If you go to the UNESCO website today and 
look for NWICO documents, you have to look very hard. They hide them. Because politically they have been bitten. They are now very shy about talking about this, and of course the world has changed.

But I still believe that it was a very important debate of its time and it has relevance - the basic arguments are as valid today as during those heated debates of the 1970 s and 1980s.

Sašo: You have written that the MacBride report remains one of the most if not the most important multilateral intervention in international communication. So after those debates it seems that the questions have died down. Has there been another attempt that you could compare it to?

Daya: Well you see, the world has changed, if you think of the context of the Cold War. Today it is a globalised world, it is a world where there are multiple poles. During the NWICO debate China was not a global player. In the 1970s they were almost having a civil war in the communist party. They were not engaging with the rest of the world. American opening had started in 1971 but it was a very difficult situation for China. Brazil was a military dictatorship, South Africa was an apartheid regime.

Today if you look at this, the BRICS (Brazil, Russian, India, China and South Africa) as a grouping has come up, China especially has become extremely important in international relations and even in international communication. The point about MacBride was that it essentially talked about democratization of international communication, that there should be plural and multi-perspectival discourse, because the discourse was, and to a very large extent, remains an Anglo-American discourse. It was the first document - because of its history and people who were in the group that wrote the final document - it was a first serious attempt to talk about democratization, plurality, multi-perspectival approaches to global communication - something which remains valid today.

Of course, it was published in 1980, we are now talking in 2016 - a lot has changed. They had no internet then. There are other means of democratizing of communication today which didn't exist then. Today you don't need Reuters telling you what is happening in other parts of the world. Within seconds you can find other information. And I think that changes things. Power relations have changed as well. You know, Tanjug used to be a central player among non-aligned news agencies. If you ask people outside certain circles today, they have never heard of it. It used to be one of the most important news agencies among the non-aligned countries.

Jernej: So how was Tanjug perceived in the international community? Was it seen as an important and serious agency?

Daya: Within the non-aligned countries certainly. Yes.

Jernej: What about other countries?

Daya: You see, when you're in a position of privilege, when you are a Reuters or an AP, why should you bother with the likes of Tanjug? It was important within the nonaligned movement, which was again not a major player. Let's not over-exaggerate its importance. For example, one of the jobs I used to do was to look at how many stories from the Pool [NANAP] had made into Indian newspapers. Every day we would monitor that. Very few, very few. Most of it was Reuters, AP. 
Jernej: And even though India was a major player in the non-aligned movement.

Daya: It was. But even in India, in India's newspapers it wasn't a prominent presence because Tanjug didn't have a large network. It had limited resources, compared with AP or Reuters who had been doing international reporting for 150 years. Over that period of time they have developed professional journalism. They have good news sources. And it's very rare that you find factual inaccuracies in Reuters or AP. What you do find are contextual inaccuracies. Context is often missing or distorted to present a particular perspective. But factually there is enough professional mechanisms to make sure that the factual element is correct. You cannot say the same things about many other agencies, even TASS.

It was important but in certain parts of the world, not globally. But if you think of it as part of this bigger project, which was the non-aligned news agencies pool, then it becomes slightly more significant. Therefore, the news organisations who had this almost monopoly - 'duopoly' because America had the most and UK was the junior partner - didn't want an alternative like NANAP, however flawed, to emerge. There was a lot of stuff written around that time, both in academia and in mass media about this 'third world conspiracy' to control information. That's how it was framed. The debate was much more complex than that.

Jernej: So there is no truth in the charges that was being instrumentalized by authoritarian countries and USSR?

Daya: The USSR used it for its own purposes, as I said earlier. It was a way to beat the US, particularly.

Jernej: But the MacBride report was very critical of USSR as well.

Daya: Sure. That's what I was saying. The group of experts which wrote that report was very international, they were distinguished people. It was a difficult task, given the political sensitivity. MacBride was a very interesting guy, he had to balance all these different pressures: the third world dictators, Soviet Union, Europeans, USA etc. I think it was a fair document in that sense. And the Soviet Union wasn't known for media freedom. These problems persist even today when Russia is supposedly a democracy. The media are controlled by Mr Putin, not just the Kremlin.

It is still one of the most significant documents. There hasn't been a follow up and it's a pity. Academics have written about it and we do occasional pieces and books about it but at the policy level there is nothing, because the debate has shifted from what were essentially very political questions about inequality and imbalance and distortion and representation to questions of access and creative industries and markets and consumers and social media. The debate has actually shifted and there are reasons for it - the world has changed. There was no Google then.

Jernej: There were also political reasons why these debates shifted from inequalities to creative industries, consumption.

Daya: Sure. Absolutely. Then you have to ask, who sets the agenda. I mean, look at the academic world for instance. Bob McChesney has written about how in US Universities, when they have a new academic position: if a political economist is retiring, 
they don't hire a political economist. It's a reflection of the bigger political changes. This critical communication research is at the margins and most of what passes for research has little critical intervention. And if it's critical it's at a very micro level, postmodern approaches to gender and sexuality and ethnicity, rather than looking at the bigger picture about the structures which affect everything: gender, nationality, race etc.

There are exceptions, with some people doing standard political economy, but not that many. It would be an interesting project to look at PhDs awarded in European universities or in US universities in communication and media in the last 20 years and see how many of these are actually about critical political economy. My colleague Christian Fuchs in one of the articles he had written a few years ago looked at the use of the words 'Marxism' and 'Marx' in academic journals in our field and he shows how it had declined in the last 30 years. I think there is, I wouldn't call it apolitical, but a different kind of politics. And not just in our field, across the board.

Jernej: In social sciences.

Daya: In social sciences in general.

Sašo: So what would you say does it mean to be critical today?

Jernej: Would you describe yourself as a critical scholar?

Daya: I would think so, yes. I think critical is somebody who asks some fundamental questions about power. Who has power, how power is exercised or misused and how it can be resisted and how that power shifts. In other words, we are looking at structures and institutions, individuals and their personal interests. It seems to me that the focus is more on that rather than mega-structures. For instance, if you look at the current situation, what is happening in the world: you have these major trade agreements: TPP, TTIP, TISA. Maybe there is work in German or in French, but in English language scholarship there is no decent academic article which looks at it from the communication point of view, how many articles or what kind of coverage has TTIP caught in mainstream media. This is going to change Europe fundamentally and therefore is extremely important for the average European citizen. Now contrast that with how many articles have been published on let's say reality TV or mobile telephony, what do you do with mobile telephony, or Facebook? Americans have made this into a high art. Actually, quite facile stuff, everyday banal stuff. It requires a lot of talent to get that into an article. I can't do that. I need content. I have never done that in my life. But I have great respect for people who manage that. They have nothing to say and they write a book. This is great talent.

But the point is more fundamental, jokes apart. The point is there is this shift. That is critical for me. Or look at 2008, it was the worst economic crisis since the 1920s. I know there have been few publications, but very few.

Jernej: Especially in comparison to reality TV.

Daya: Or other things. There are now about a hundred journals relating to media and communication. I edit one. A hundred journals! Most of what gets published is a kind of business, people just churn out stuff. Because they have a project, they have got 
to show that they have published after that. And there are all kinds of mechanisms in place, you have to publish in particular journals. And that's the debate on how ...

\section{Jernej: How academia works?}

Daya: Instrumentality of intellectual life, how that has changed and what that means to reflective or critical work. For example, I tell you, I'll get back to Oliver Boyd-Barrett as an old friend. We did this book, I mentioned earlier, Contra-flow in Global News, in 1992, and I have known him since 1988. He wrote a book, it came out in 2014, simply called Media Imperialism, published by SAGE. It's a very decent book and he's a well-known name. It was totally ignored. There were hardly any reviews because the subject is unfashionable. This is a 1970s discourse. Herbert Schiller is gone. These things are not important today. I'm very pleased that my colleague Christian Fuchs is bringing these things back. But there are not that many Fuchses around. [laughter]

To my mind being critical is extremely important, but I also bring something new to the table in the sense that political economy, for example Herb Schiller's work or Oliver's work, still operates in a narrow, Western view of what culture is, for instance. For example, when I came to the UK for the first time in 1988 somebody asked me Dallas was a big thing at that time, 'Dallasization' of the world - so somebody asked me: 'Who killed JR?' It was a character in the series. And I said: 'Who is this guy?' And they looked at me as if I had come from another planet. They couldn't imagine that in India we didn't have Dallas. We had our own rubbish, but we didn't have American rubbish.

India is a very big country, a lot of people. In China there was no Dallas and that's another very big country. So, we're talking about $40 \%$ of the world's population which had nothing to do with Dallas. There was - and to some extent it continues - that rather Eurocentric view of what the problem is. To me that is a fundamental problem. I have written about it. It's been my endeavour to broaden it a bit. So, for example: China. In relation to media and communication the dominant frame is censorship. What we have forgotten in this frame is that the Chinese, by retaining this censorship have developed what I call 'cyber capitalism with Chinese characteristics'. They have their version of Facebook; of YouTube, of Google and some of these organisations like Alibaba are now operating globally. I can't think of any other country ... Russia has it too but not as big. There is no Alibaba in Russia. By retaining this control they have been able to develop their own. Germany hasn't done it, Britain hasn't done it. So maybe there is a problem in the way that we frame the debate. It's very narrow. We think that if you can't read the New York Times you are deprived. I say to my Chinese friends: 'What does it matter if you don't. It's just a newspaper.' I think that requires slightly out of the box thinking.

And I have been privileged because I come from a slightly different background. The advantage that I have that my Western colleagues don't is that I know the Western discourse inside out. I am educated in it. But I also have other things to draw on, which they don't. You see what I'm saying? That is a very interesting shift now. So, you might be an Iranian scholar who has a grounding in Islamic thought but is also very fluent in Western discourse. I think that is what makes it a bit more complicated because academia is more diverse today than before. Not so much here but in UK, US certainly and that's changing the way we see the world and these broad generalisations, assumptions that we have about the world - these are being challenged. And I think that what is happening in China is very significant from that point of view because the scale and scope of change is so profound. We may not appreciate it so 
much in Europe, but if you're in Africa or in Asia or in Latin America it's a very different story. That's the majority of the world.

I published a book some years ago, in 2009, called Internationalising Media Studies which emerged from a major conference which I had organized at the University of Westminster and the key reason was to say: OK guys, we have got to broaden the discourse a bit. I did not want to use the phrase 'de-Westernisation' because it has a negative connotation, because there's a lot of valuable work done in media and communication studies in the Western world, in the US, in Germany, in UK. What needs to be done now is to expand that. How do we think of the world in critical terms but not based on derivative approaches? How do we use Habermas to explain what is happening in Iran for instance? That requires a lot of work. One book, one conference, one individual ... it takes a lot of time and a lot of people have to get together to talk about it over a period of time to develop an alternative. And I think something is already beginning to take shape. In a very modest way I try to push that a little bit. At least raise the issue. I don't have answers but I raise the issue.

And to be honest, the response has been very positive across the world. For example, I edited a book on Contra-flow in media in 2007, the first book looking at the kind of emergence of non-Western media. Again, the main argument was that there is a lot happening outside the Western world in terms of media and communication, whether it is Korean pop music or films, Al Jazeera or Bollywood. And that is increasingly affecting international communication. Some of the critical questions about ownership and structures and how they operate in trans-nationals are as relevant today as before. It doesn't matter which country you study, which media, they are fundamental. I'm not saying you can abandon them. What I'm suggesting is to incorporate all this in a discourse which is slightly more sophisticated, which is not just dogmatic in a manner of speaking. One of the problems of Marxism was that it has a very limited view of culture, a materialistic view of culture. In fact, culture is much more than who owns what. So, I think one thing that cultural studies and postmodernism - we were talking earlier about this shift - one thing it has done, it has actually made political economy more conscious of this aspect.

Jernej: So there were positive changes too?

Daya: Exactly. Also, the kind of power equations which have forced people to think again about China not just as a peasant society but as a serious international player. Or India as a country of superstition, religiosity and backwardness. I mean they were able to send a vehicle to Mars last year at the cost of a Hollywood film. They were able to implement the world's largest IT project, it's called Aadhaar (foundation in Sanskrit) Have you heard of it?

Jernej: No.

Daya: Proves my point. This is a project which gave a billion people ... Slovenia has two million people? A billion people - every citizen in India has got an electronic identity card and it was done in five years. It's astonishing.

In the last 20 years, China has raised 400 million people out of poverty. This was not achieved by Oxfam or European Union funding or some American NGO, it was done by the Chinese state. There are certain things happening outside of the Western radar, to me these are extremely significant. They have already changed the world and in the next 20 or 30 years they are going to change it much more. It is in- 
cumbent on intellectuals, therefore, to address these emerging issues and engage with them. Especially in the western world it's extremely important because as I have said earlier: the rest of the world, they know the West, but they also know something else. The West only knows the West and that is the problem.

Jernej: But you need a very broad perspective as a scholar.

Daya: If you read the Guardian and New York Times you should know this. You should know about Aadhaar.

Jernej: But I'm talking about for example TTIP or stuff like that. You need a wider knowledge as compared to if you only write about Facebook which is a very narrow perspective. It's much easier. That's my point.

Daya: That is the problem in the western intellectual tradition. It is reductionist. And because of that it is all very good: you are looking at one particular aspect and doing a very detailed analysis of Facebook for example, and you get published and it's very thorough, properly researched. But you miss the elephant in the room. The tradition where I grew up is a holistic tradition. It's a very different intellectual tradition. I don't want to sound nativist but it's a Hindu-Buddhist tradition, which is some ways fundamentally different from the Judeo-Christian tradition, which is based on 'the book', the law. There is 'either/or'. In the intellectual tradition, I grew up in, it is always 'and'.

Jernej: So you would connect this to cultural differences?

Daya: Absolutely. Has it ever occurred to you that in every university in America, top university, you'll find an Indian professor and she would be top of her rank. Why is that? India is an extremely poor country. The facilities that most universities have there are appalling even today. There must be something in that culture which sustains intellectual culture, and to me that something is the capacity to have a pluralistic view. Not 'either/or', but 'and'. Holistic view. I think that is to me fundamentally important because then you can look at this as a matter of interpretation. You say ' $x$ ' and I say ' $y$ ' and that is fine. Under Marxism I only believe in ' $x$ ' and everybody else is wrong. Or the other way around. I think that is something which is extremely valuable.

And it's not just an Indian tradition, it is a broadly eastern tradition, which has its roots in Hinduism or Buddhism. It believes in multiple ideas and I think as India becomes more important - economically it is already the third largest economy in terms of purchasing power parity - it has extraordinary potential and such ideas will circulate globally. The middle class numbers 300 million people, highly educated, English fluent, able to deal with diversity in a way that a lot of other people can't. World's second largest diaspora. World's largest English speaking diaspora. In a globalised world, this is going to become very important.

So, I think it is important for people to engage with those Indic ideas and ideas coming from China. Already some very interesting work is beginning to take shape in China. It's happening in Chinese so we don't know it. Because I'm also a research advisor to the China Media Centre at our university, and in that privileged position I get access to many Chinese scholars who tell me about what the debates are and it's fascinating. 
Jernej: Could you give us some examples?

Daya: Well the way they think about the world for example. It's not just when they talk about this whole peaceful rise, harmony ... it's not just state propaganda. Thinking seriously about how we need to provide an alternative to the largely American discourse about how the world is governed. Essentially, it's about power. If you have the power, people will listen to you. Everybody is queuing to go to Beijing and parts of London are now owned by the Chinese. Chinese university students today constitute a large proportion of postgraduate students in many Western countries: If they withdrew tomorrow many of us wouldn't have a job, because essentially the Chinese students pay our salaries! We sometimes assume certain things. For example, the idea of modernity is associated with European enlightenment. The implied assumption there is that before that people were not rational. That's stupid. There is a lot of history written, recorded history saying that is not the case. Chinese were printing books a thousand years before Gutenberg happened.

Sašo: So it's very euro-centric.

Daya: No, no, this is just wrong. Because if you are a Chinese kid you know it. You don't need to be told. But a European child - an American child knows very little history - but even a European child doesn't know this. It's not so much about university, the problem stems from a more fundamental level: at school.

There is this fantastic book by a former diplomat in Singapore, Kishore Mahbubani, now he's a professor: he talks not 'rise' but 'return' of Asia. Until the 18th century, $60 \%$ of global GDP came from Asia, led by China and closely followed by India. The problem is about how knowledge is structured and that hierarchy is fundamentally being questioned. I think it's going to get more complicated because essentially people are going to say: is enlightenment just a European idea? Europe wrote the modern world's history but the world is much older than 200 or 300 years. In a book about 'soft power' which I published in 2013, I mentioned the great scholar and strategist Chanakya (also called Kautilya) I don't know if you have heard of him, have you heard of Chanakya?

Jernej: No.

Daya: You've heard of Machiavelli? Machiavelli wrote The Prince in the 16th century. Chanakya lived in the third century BCE and his book is called Arthashastra. In my book, I asked 'Shouldn't Machiavelli be called the Chanakya of Europe' rather than the other way around? Because the difference is of 1900 years, and what Chanakya wrote was far more sophisticated and much more detailed than what is in The Prince. This is just one example, there are numerous others and these are going to be raised.

There is a lot of debate going on in India right now because the current government is right-wing and they are trying to extricate a particular kind of history, a project which is politically motivated. But it is also showing that there is a debate beginning to take shape which is challenging some deeply held assumptions about who we are, where we came from, what is our history. It is a more general point but I think it has also something to do with communication and media. For instance, if you look at journalism history books in Europe or in America and see how much there is about the rest of the world in these books. 
Jernej: There is basically nothing.

Daya: The assumption is that there was no journalism in these countries. The Times of India was established in 1838. When I look at this, I just say OK, fine. I don't get cross because I understand exactly where they are coming from and why they do what they do. Because the idea is that we have the theory and we apply that. Case studies are in what used to be called the third world. We go and say OK, we've done case study of Somalia or from wherever ...

Sašo: But I think there is also a paradox there when you mentioned earlier that in India journalists would more often rely on Reuters for example than on non-aligned news agencies. Could you say that they had this western conception of what it means to be a journalist in which these professional standards like being factually accurate and so on are more important than creating a more holistic picture, giving context, balancing out the perspectives of the global north and south and so on.

Daya: Well the thing is the journalism practices in countries like India are very much influenced by the British model, not American, because of historical circumstances. They would not think twice, they would say: 'OK this non-aligned thing is just government propaganda, that's not serious journalism. Reuters or AP is proper professional journalism.' These are professional organisations. They've been doing this for 150 years or more. They have access all over the world and they do a professional experience and expertise.

And then there is also the question of journalistic routine. From Reuters, for example, you receive a clean copy which is perfectly adequate. With the non-aligned news agencies pool you had to re-write it. It was so badly written and you had to make it look professional, take all the adjectives out. You wouldn't say Zionist entity for Israel but lots of Arab news agencies at that time didn't use Israel. Journalists operate on a very tight schedule and they don't have time to reflect. Academics do that. We have time to say 'what is the context'. Journalists are doing a very routine job. But the point you are making is right in the sense that the tradition is very much a British tradition. That's why it's a better journalism than in many other developing countries.

Sašo: I think from your writing also this paradoxical nature of media globalisation emerges. So on one hand we have new players emerging so that the flows of international communication and information are not so one-sided, just coming from one way. But on the other hand you write how this basically US model of commercialised media is becoming universal. So I think there is a paradox there. The United States is losing its position but its model is becoming the universal model.

Daya: Absolutely, because that model is based on certain attributes which work across cultures: selfishness, profit, influence. Even in China where the state is very much in control, they are encouraging marketization, especially at the regional level, advertising is growing very rapidly. I don't see this as a problem because that paradox is the reality in my view. There is a kind of resistance to this also at some level, but that's more rhetoric than reality. The reality is that this works so we should follow this and for the US it's a great way to get into new markets.

For example, in China there are limitations: you can't show, Hollywood films. What Disney is doing, they're saying 'we'll do collaborations with you, we'll do joint projects 
with you, we'll teach you how to make films' and Chinese are saying 'fine, we want to develop our film industry'. So, it's very pragmatic at that level. I don't see that necessarily a problem. I'm just stating what is happening in the real world.

Sašo: But these countries like Russia, India, and China also very consciously chose this path, to become integrated into global markets.

Daya: Yes, but the models are different. The Chinese model is quite interesting because here the state has played a crucial role. It's capitalism with Chinese characteristics, that's how it's been defined before by others. In fact, there is a book being published by Canadian scholar Daniel Bell who is a professor of politics. He is based at Tsinghua University and the book is called The China Model. He's not talking about economics, it's very interesting. He's talking about politics. He's saying 'here you have a meritocratic government'. I'll admit that the Chinese government is meritocratic. Like mandarins, they have to go through various systems to get to that level. It's not to say it's not corrupt. There are all kinds of things like anywhere else, but it is ostensibly more meritocratic and it has delivered in many spheres: domestically and even internationally. Therefore, the argument is that it is a different kind of model that it is a kind of state control. Human rights are controlled, news is managed, information is managed, but entertainment is OK. Certain areas have opened-up.

So, there are different models, and China is particularly interesting. In 2014, it became the largest economy in the world in terms of purchasing power parity and last year the IMF finally allowed the Chinese currency to be one of the elite currencies in the world, a significant move.

It requires a different kind of thinking of the world. The assumption in your question is that capitalism is Western.

Sašo: I do think it has western origins ...

Daya: I'm questioning that. The BBC recently screened a six-part series called The Story of China. Six hours of television, presented by Michael Wood, a well-known television historian. Please watch it, you'll feel humbled. I'm a reasonably educated person, I know a little bit about the world beyond the western world. I felt humbled. So, the notion that it all started with capitalism and the rise of Protestantism and all these books we have read, it's beyond that. There is much older history of capitalism. They didn't call it capitalism, but it's a much older history of how people traded.

Jernej: Well it depends on how you define capitalism as well.

Daya: I'm saying that is more than capitalism of a particular historical juncture and we are assuming that what is happening in China is just going to continue in the same version. They might have a different way of thinking about it. Actually, for the last 30 years they have shown they have a different approach and we should take notice of that. I don't want to sound like an advocate for Chinese authoritarianism, I'm not. I grew up in very free country and I live in a very free country. I wouldn't like to work in China or live in China. As an intellectual, I would feel constrained but at the same time I look at my own country - India - and I see that despite all this economic growth it has 300 million people living in abject poverty. It has a stable democracy (the world's largest), great intellectuals at universities but it has failed a lot of its people. China is a different story. There is poverty, there is inequality, there is corruption 
but not at the same scale, they have moved on. So, there is a question whether democracy is the best answer to these problems or meritocratic government that gets on with things: 'OK, we've got to do this, we've got to educate women, bring health service, do basic things that are missing in a lot of the developing world'. If you're sitting in Ethiopia or Peru and looking at American discourses on aid and human rights and Chinese investment, I'm very clear in what they will prefer.

I think that aid issue is very interesting as is communication about aid and migration and refugees. A lot is written on this. Last year there was a big debate in the UK about whether Britain should continue to give aid to India. The argument was that India is now doing OK economically, that it doesn't need UK aid, that the aid should go to poorer countries or stay in the UK. And one British academic reminded the BBC that the annual budget of British aid to India was something in the range of 400 million dollars while the annual development budget of the government of India was 74 billion dollars. So, aid to India is not even a bad joke, it gives some jobs to the NGOs who will visit India, the BBC will go with them and report how Oxfam, for example, is feeding children in slums. Such aid is marginal and this is the case across the world. I think we need to be a bit more careful about reasserting those assumptions and be more self-reflexive. Maybe we have certain preconceived ideas about how the world is and maybe the world is not like that.

I have been living in Britain for 30 years and Britain claims to understand India. For 50 years expert professors in Oxford have been saying that this country will disintegrate. They have been saying that it is an artificial nation and that we gave them the English language, that we gave them the railways, we united them. Quite the opposite has happened. India is an infinitely more powerful country today than it was 30 years ago. I say that because this is something I know from first-hand experience. You could make the same argument about Iran. There is so much written in the mass media about Iran's nuclear programme. That is the main story from Iran. Iran is a signatory to the nuclear non-proliferation treaty, unlike India and Israel, which are not. Both India's nuclear programme and Israel's nuclear programme are in violation of international law. Unlike Iran's, which is legal. Just think, how many times have you seen a story - forget about Israel for a moment - How many stories have you seen critical of India's nuclear weapons programme?

Sašo: I don't think I have seen any.

Daya: I rest my case. What I'm trying to get at is the more fundamental question about what it means to be critical. Not if I'm Marxist or I'm not Marxist, to me that is banal. I think we need to move to the next stage and say OK, let's be more open to different ideas and perhaps think of a new critical, a globally relevant critical discourse. Of course, political economy will be prominent in it because it has traditionally looked at structures and institutions and the material aspect, which is crucially important. But that can't give us the whole story. And that has been my academic endeavour and in a very small way I have always done that. I'm very conscious of how limited our impact is. I don't live in a cloud. I know exactly how limited it is but that's all we can do. We can put up some signposts, some markers and somebody might pick them up. And then somebody else. It's not going to happen in one generation, these things take time.

Sašo: I see a lot of development in terms of market oriented development, I think the current government of India is certainly very pro-business, pro market oriented. Or I 
look at media that are penetrating into the west, a lot of them state sponsored like Russia today or Al Jazeera, but how about potentials to democratize media? That was in my view one of the most important points of the MacBride commission. It's not only about these global imbalances, it's about democratizing communication, making it a dialogical exchange not controlled either by the market or the by state.

Daya: Sure.

Sašo: Do you see any developments or what are potentials for that kind of developments globally?

Daya: Well I think the internet offers a lot of potential for that. Some of that has already emerged and it's growing. Many transnational connections are emerging, whether it is about the environment, for instance, or political discourse etc. That has happened. But to me that is still minor in terms of impact and therefore the big guys matter: the Murdoch's of the world or Google's of the world, whether it is Russia or EU or China. In fact, I'm currently writing a book The Changing Geo-politics of Gobal Communication. Hopefully it will take 2 years for me to finish it. I'm looking at some of these issues about the rise of for example RT, Al Jazeera, whether this leads to globalism or is it just propaganda, back to the Cold War.

I think for somebody like me who is not Russian or Western, I'm an Indian scholar who works in London, for me RT is a great source of a perspective that I don't get on CNN or BBC. For example, there is a whole discourse about NATO's eastern expansion. What you often get is marginalized in one sentence, but in RT that is the main story. Or on Syria there is a story which we don't get in mainstream western media. So as a student of international communication I find it fantastic that I can watch something coming out of Moscow in a language that I understand and I'm aware that this is coming from a particular perspective. I know it's essentially Putin's viewpoint, but there might be some legitimacy in that viewpoint as well. Why should we assume that the BBC or CNN is telling us the whole truth when there is overwhelming evidence to show that traditionally they only present a slanted perspective?

Sašo: It's interesting to see how one perspective becomes neutralised and the other is particular propaganda. If you look at how the BBC covers ...

Daya: Yes, to you but not to me! For me it's not propaganda.

Jernej: But it's portrayed as such in a public discourse.

Daya: But whose public discourse? That's the point. I know that but I'm looking at it beyond that. What do you expect CNN to say?

It's interesting because I was at a panel in Berlin last November and we were talking about media plurality and somebody asked me the same thing about RT and what do you think about propaganda. I said exactly what I said to you now. I benefit as a student of international communication to have access to that information. Ten years ago, I didn't have that so I didn't know what the Russians were saying on Syria for example. And I mean, this is just one channel. Now on the internet there is so much more material available. In fact, there is too much so you must be able to sift the rubbish from good information. I take that as a positive development and in some 
way it helps to fulfil some of the ideas raised in the MacBride report about a multilingual, multi-polar and multi-perspective world.

We can't be all listening to what the Americans have to say about the world because there is a fundamental structural problem: If the US government is directly involved in bombing Iraq, as it was for many years and continues to be, we're getting information about Iraq from US media. We are not listening to what the Russians are saying about Syria now, we're not watching Russian TV although they have done a lot of interesting work there. The tragedy is that supposedly educated people don't see it. I see it with my students: they can't go beyond RT as a propaganda. Of course, it is propaganda of a sort, but the BBC isn't different in that respect.

Sašo: Recently the former director of the BBC Peter Horrocks said publicly that the $B B C$ needs more funding because they are losing the information war with Russia.

Daya: The assumption is that we are part of a propaganda war. That statement - the assumption is that and indeed there is a propaganda war going on - a neo-Cold War information warfare.

Sašo: It was interesting to me that it was so frankly said: the BBC has to be among other things a propaganda tool of British ...

Daya: During the Cold War, it was very prominent and since the end of the Cold War it has been very prominent, it's nothing new.

Jernej: And it also spreads to press agencies which are also western but are also instrumentalized for political reasons.

Daya: Of course.

Jernej: Which you also point out in your books.

Daya: I say to my BBC friends: 'Look guys, you have got to grow up because you are not in China. You are not allowed except in 5 Star hotels. In India, the audience is so small it doesn't even register on any measuring mechanisms.' There are 400 news channels in India. BBC is largely irrelevant. In the Arab world, they have over 100 of their own news channels. Every major European country has its own news. BBC might be in 5 Star hotels and somebody might watch it, but it's not the main source of news. In Latin America, it was never strong. In Africa, the Chinese are coming in a big way. So, I say to them: 'Grow up. Learn some modesty. Don't try to lecture people. You're in decline and if something happens to the City of London - You have little else.' It's a vulnerable situation and I think they are pragmatic enough to realize it.

What is increasingly happening now is that they are focusing on such genres as game shows. BBC Worldwide is the commercial arm of the BBC and they do a lot of programming and they are very successful in creating formats which are sold all over the world and that's non-political and it's not a problem. That's not to undermine their professional news standards. They are good, they are the most respected broadcasting organisation in the world and they have a very long tradition of providing good professional journalism but there is also this kind of mind-set which is yet to fully recognise the realities of a rapidly changing world. 
Jernej: You have connected both commercialization and the spread of power of television to infotainment.

Daya: Yes.

Jernej: Could you tell us more about it? How is this influencing, what are the consequences of this rise and spread of infotainment?

Daya: I did this book in 2007. It was the first book to look at television news specifically at an international level. The core argument of the book was that infotainment works as a very skilful and largely successful diversion. So, you keep people busy with Bollywood or Super-girl in China or Big Brother in Europe. Doesn't matter what it is: some version of diversion in television programmes. In the process the more important issues that deserve attention, I was talking before about the trade deal which will change everything, they get displaced. I called it an instrument of neoliberal imperialism, that's the phrase I used. Because there is no coercion involved, this diversion very cleverly legitimizes a particular kind of economic system, which is essentially neoliberalism.

China as a consumer market is, not quite yet, but going to be the largest in the world. It is by the number of people but it will become the biggest also in terms of value in the next five years. So, the Chinese government wants to increase domestic consumption. Infotainment is good for that. And there is an ideological dimension which I wanted to emphasise.

I just don't have the time at the moment, but I've been thinking about doing a follow up. I was going to call it 'Infotainment 2.0', infotainment in the age of the internet and social media. The book was really about television and today, a decade later, if I look at the issue of diversion today it is mostly the internet. It's very fragmented and much more dangerous in a way because now with data mining and geo locations, they know exactly what you're doing, where you're going etc.

That is not to undermine what is good about infotainment. In the book, I have a section where I talk about 'good infotainment' where you can bring some serious issues on the news agenda, which normally would not be covered by television news, by making them more accessible and entertaining.

Jernej: But there is huge corporations on the internet as well. They dominate the internet ...

Daya: Exactly.

Jernej: It's basically more or less monopolised now so it leads to possibilities of ... it's not repression, it's actually we voluntarily repress ourselves.

Daya: Yes. We give them information, we tell them what we like, we press 'Like' on Facebook and they know exactly what we like so they don't need to do any marketing. We are doing it for them. But you see, it's like the double-edged sword. At one level, there is this potential for repression and control, but on the other side it also has potential to democratizing communication. There is so much there in cyberspace which is fantastic. You can visit the best museums in the world and have a virtual tour, you have professors who give lectures for free, you have high quality stuff, you 
can get government reports, and you can get corporate data. It's a fantastic source so we need to have a little more cyber literacy.

But the other side of that is what I call data driven scholarship. Everybody is doing quantitative research because there is a lot of data.

Jernej: And again there is no context.

Daya: There is no context. And there is no critical involvement. It's 'how many people are using Facebook?' A lot of stuff is published. And you read the abstract, you don't read anything else, because it is just a waste. OK, somebody gets a PhD, somebody gets something published. [laughter] That's fine, I don't have a problem with it. But it is not something which makes you think and the whole point of university life is to stimulate thinking, to disagree, to argue. We are not doing that enough. We are increasingly following a very conformist path.

Sašo: It's interesting also that more and more data is not public but privately controlled. Facebook has a massive amount of data about its users and if you want to do a PhD using Facebook's data you have to go to them and say 'OK, I want to analyse your data,' and they'll respond: 'What can you offer us?'

Daya: Absolutely. There's lots of sponsored research now, it's not unusual. We are very fortunate we live in Europe where there is a tradition of autonomy of universities and we have freedom to do what we want to do. But even that is changing now. There is this hierarchy where you should get published and kind of rating/standing of the journal matters - and I find that quite problematic to be honest. It creates a certain kind of instrumentalisation of scholarship and publication. I'm personally against that.

Jernej: But in a very general sense you were critical of infotaiment, of its consequences ...

Daya: Oh yes! If you read the book - extremely critical!

Jernej: What are the key consequences for democracy? The fact that we would like to live in democracy but ...

Daya: Well that's true. US is very good example of that.

Jernej: With Trump?

Daya: They elected Bush twice, not once. He was president for 8 years.

Jernej: But Trump is something qualitatively outside of that as well. It's beyond ...

Daya: If you look at US television news - infotainment is supreme.

Jernej: So it is celebrity obsessed ...

Daya: Sex, scandal, sport ... And increasingly now it's happening with the newspapers too. Although my focus in the book was on television news but in newspapers too this is happening because the pressure of the marketplace is so strong and they 
are losing readers and advertising revenue. There is an increasing amount of sponsored content, which is another form of diversion. It doesn't add to your knowledge or understanding. Even as good a newspaper as the Guardian is now indulging in all that because it has to survive. It's losing millions every month so it's trying every tactic to engage its readers.

Sašo: I think this is one of the instances where the situation is drastically different in the West as opposed to for example China or India. This crisis of traditional business models of journalism or newspapers especially. I believe India's newspapers readership is still on the rise.

Daya: Yes. Because literacy is growing, people have more spare money, the economy is growing. Because the base is so low. But as the internet spreads more widely the problems that they're facing here in Europe or in the US will appear in India. China already is starting to have that problem, the internet access in China is $50 \%$. In India, it is around $30 \%$ as of today. When it becomes $80 \%$, which is likely in the next 5 years, since they're spending a trillion dollars on infrastructure, then the same issues will appear.

I think there's a bigger problem across the world with what kind of journalism should we have for the digital age and how do we monetise digital newspapers - that is still a problem. Even big brands like New York Times are not making a lot of money on digital versions.

Jernej: If we take just a step back again to the 1970s and 1980s to questions of cultural imperialism and the thesis of dependency theory. Do you think these still have value today or are they obsolete?

Daya: Not at all, I think they are very valid. I already mentioned Oliver's book that came out in 2014 , it's a very good book. What he has done, he has brought it up to date, looked at electronic empires if you like, the Google's of the world and how extraordinary powers they wield today, much more than newspaper magnates ever did. Because they are global, their presence is not just in one country or one region. So, the idea of dependency is very relevant in that debate. The idea of control and power is very important although the imperialism word is coming back. It's interesting, Christian Fuchs has been writing on that as well, and Oliver's book is published in 2014 so these people would not be using these words if they were not relevant. I think there is a currency to this, and some people are talking about Chinese imperialism now, in Africa for example, it is a new kind of imperialism. So this terminology is coming back. Its relevance hasn't gone away.

Jernej: So to conclude: do we need a MacBride report for 21st century?

Daya: We possibly do. It would be wonderful to have another similar report for the digital age.

Jernej: Is it even possible? That is the question, because the historical circumstances, the geo-political context is completely different.

Daya: It is. That's right. You see, the thing is, there is also the whole idea of the information society, how this debate came into WSIS, the information society became 
a big thing, which was more about data and interconnectivity. Basically, they are doing work for big American corporations, whether it is Microsoft or Google.

So, I think the time is right for a revival of that report, for getting some people together from industry, from different governments ... One big debate is about internet governance, how that is going to be done, because there are already different models. The Chinese have their own version, the Russians have their own approach and there is the dominant idea that it should be open and private.

There are other forums where these things are discussed, but it would be good if something like UNESCO or ITU was to take initiatives and get some people together from industry, from government, civil society and academia to address some of the issues that were raised in that report.

But I don't see much happening. Apart from academics who are sort of interested I don't think ... in my experience policy people are not that bothered.

It's important to remind ourselves that today in this changed geo-political situation, the budget of the Bill Gates foundation, is bigger than the budget of the World Health Organization. That puts things into perspective. The biggest UN organisation which deals with global health: its budget is smaller than a US based private foundation.

Jernej: So these inequalities have rapidly expanded and not for the better in any way?

Daya: Let's not undermine what the Gates foundation has done: it has done some fantastic projects around the world, really successful ones and in some ways people have argued are more efficient than government's projects. Because there's less corruption, less bureaucracy etc. So it's a more complex picture. But the answer to your question is that we need to revise the MacBride report and have a 21st century version of it. 